\title{
Performance measurement of supply chains and distribution industry using balanced scorecard and fuzzy analysis network process
}

\author{
Fausta Ari Barata ${ }^{a^{*}}$
}

${ }^{a}$ University of 17 Agustus 1945, UNTAG Surabaya Indonesia

\begin{tabular}{|c|c|}
\hline CHRON I C L E & A B S T RACT \\
\hline Article history: & \multirow{12}{*}{$\begin{array}{l}\text { This study aims to identify effective indicators in the performance measurement of a firm using } \\
\text { Balanced Scorecard (BSC) as well as weighting and ranking indicators by employing Fuzzy } \\
\text { Analysis Network Process (FANP) and investigation on network mapping and the relationships } \\
\text { between balanced scorecards with Fuzzy DEMATEL presenting strategies to improve } \\
\text { performance of a firm. To assess the significance of the four perspectives: financial, customer, } \\
\text { internal processes and learning and growth, about } 28 \text { indicators are identified, and after } \\
\text { screening, } 13 \text { indicators are located as final BSC indicators. After examining the influencing of } \\
\text { the main factors using fuzzy DEMATEL technique, internal processes dimension has the most } \\
\text { impact and customer, and learning and growth and financial dimensions respectively are ranked } \\
\text { as second to fourth priorities. Also using the Fuzzy ANP technique has examined weighting and } \\
\text { ranking of dimension and performance measures indicators that dimension of customers has } \\
\text { gained first rank and financial, internal processes and learning and growth are ranked as second } \\
\text { to fourth respectively. }\end{array}$} \\
\hline Received October 28, 2020 & \\
\hline Received in revised format: & \\
\hline & \\
\hline Accepted January 272021 & \\
\hline $\begin{array}{l}\text { Available online } \\
\text { January } 27,2021\end{array}$ & \\
\hline Keywords: & \\
\hline Performance Measurement & \\
\hline$B S C$ & \\
\hline Fuzzy DEMATEL Technique & \\
\hline es & \\
\hline & \\
\hline
\end{tabular}

C 2021 by the authors; licensee Growing Science, Canada.

\section{Introduction}

Present organizations noticed that to survive in the global business environment, the quality of their products and services can attract new customers while retaining existing customers and thus increase their income (Stwart \& Mohamed, 2001). To achieve this, it is possible only through the application of correct management. Quality is restored; also management needs various tools to improve quality that one of these tools is the implementation of quality systems. Originally total quality is a culture that became a tool. It should form comprehensively in the mind of each employee so after a while mental concepts become action and used as a tool enhancing quality in organizations (Falsafi et al., 2010). In recent years due to the weakness of traditional assessment methods and changes in the competitive environment, new models have been provided for the performance measurement of the organization. BSC approach is one of the new models. Previous studies show that this model provides a suitable framework for measuring performance and many companies in the world have attempted to implement it. This method added three dimensions to traditional financial evaluation such as customers, businesses' internal processes, learning, and growth (Kateb \& Hasanabadi, 2007). Present organizations unlike the traditional organizations believe that must constantly improve their cycle based on Deming logic is a continuous program. Various aspects can be obeyed in performance measurement and planning. One of the important concepts in the literature can be based on the BSC approach. This approach can measure four different dimensions of financial, customer, activities, and training (growth) for each system or subsystem as per said before. However, can always be used a wide variety of indicators and criteria in the field to assess the dimensions which confuse the senior decision-makers. For this purpose, it is necessary for the organizations and the system under study, possible indicators to be identified, and based on a solid logic evaluation. The quality management system is one of the most effective systems for the delivery of high-quality products or services and will have an undeniable role (Nelly, 1999). This system as representative of quality management thought can be measured by performance and hence it is necessary for two consecutive phases but independent. First, effective factors in this field identify and rank based on FANP techniques and using concepts of BSC and then in a second step, it is necessary to examine the relationships between variables based FDEMATEL methods for identification and the relationship * Corresponding author.

E-mail address: baratafaustaari@gmail.com (F. A. Barata)

(C) 2021 by the authors; licensee Growing Science, Canada. doi: $10.5267 /$ j.dsl.2021.1.004 
between criteria and building mapping relationships in a network. In the late 1980s, a growing number of managers in the various units of industry such as commerce concluded that traditional management and financial accounting for their companies do not have enough power to give complete information. In 1992 Professor Kaplan and Dr. Norton founded a new method to measure called BSC. Traditional BSC breaks financial limitations, measures organizational performance in terms of the four main features of financial, customer, internal business process, and learning and training (Khorshid \& Zabihi, 2010). Momeni and Faal Ghayomi (2011) and Feizi \& Solookdar (2014) in their research evaluated the performance of the banking industry and confirmed the necessity of using multi-criteria decision-making techniques (MCDM) phase to achieve more tangible results of the evaluation. Also Feizi, Monooei \& Hashemi (2013), in a study to assess Tehran's municipal development company with a BSC approach have pointed to tangible results of this method (Valmohammadi \& Foroozeh, 2010; Kaplan, et al., 2000; Karsalari \& Hashemi, 2012). According to these developments, measurement systems must be designed following the status and functions of the manufacturing organization, industrial, and education, and since the majority of managers do not know the performance measurement criteria and measures have not properly developed and defined. This issue also increases the necessity and importance of this study. Despite the importance of this issue and the growing trend of different organizations and institutions, including manufacturing and service in many countries in line with the implementation and application of quality management system, the implementation of this management approach in the Persian service companies (especially Company Firm) has not seriously considered and its implementation has faced several problems and obstacles. In a way causing that quality management has not successfully been implemented in various service organizations that this issue, in turn, leads to stagnation and decline in the quality of various aspects of internal service. Certainly, the first step out of such a situation and taking steps towards the establishment of quality management in service organizations and companies to improve quality, plan and carry out studies about exact identification of key indicators is facing the implementation of quality management.

1. The real question is how can organizational performance based on BSC and MCDM tools to be measured in a quality management environment?

2. What indicators should be considered to assess the performance of the Company firm with the BSC approach in a quality management environment?

3. How is the relationship between the variables, the relationship between criteria, and building network relationships mapping using the technique of fuzzy DEMATEL?

4. What is the order priority of indicators in assessing a Company firm with techniques of FANP?

This study aims to measure the performance of a firm in four perspectives (financial, customers, internal processes, learning, and growth) and determining key performance indicators related to the BSC in that field and ranking indicators using the technique of fuzzy ANP so is measured amount of their impact on the firm's performance and managers can take steps with a focus more on effective indicators to make decisions about future goals of the company and also is provided a consolidated model of BSC (performance measurement tool) and fuzzy DEMATEL-ANP (tool of make decisions). The output of this research can be considered as a comprehensive assessment of the quality management system that will provide foresight and make improvements for the authorities in charge of quality. In 1983 Professor Kaplan criticized traditional management control generally and performance measurement in particular. This thinking continued until in 1992 Professor Kaplan and Dr. Norton in an article titled "The Balanced Scorecard: Measures that drive performance" introduced the BSC framework. This method had such an impact on the organization that expressed in 1996; BSC is the largest business development during the past 75 years. BSC from development time in the early 90 s has been changed from different angles. Fig. 1 shows the evolution of the BSC. BSC provides a framework to describe strategies to create value for customers, shareholders, and citizens that needs a mission and vision to fulfill it in any organization. BSC perspectives that traditionally have been introduced by Kaplan and Norton have needed reform and review to encompass two new areas (employee satisfaction perspective and the perspective of the environment and society) (Alam Tabriz \& Rahimi, 2009). These two areas are related specifically to human resources teams. These two perspectives were not considered in the original model by Norton and Kaplan. Having an employee satisfaction perspective separately among BSC perspectives will be indicating the importance of this factor and a key driver in the organization. The perspective of the environment and society (communication) helps to create a large investment for the team of human resources and in this regard, helps the organization (Rezaei Ghahraman \& Aghahosseini, 2011). Table 1 shows six perspectives of BSC (Rezaei Ghahraman \& Aghahosseini, 2011; Zhang, 2000; Nilipour Tabatabaei et al., 2007; Khakbaz \& Karbasian, 2011).

\section{Table 1}

Six BSC perspective

\begin{tabular}{ccc}
\hline internal processes Dimension & Customers Dimension & Financial Dimension \\
\hline $\begin{array}{c}\text {-The timely delivery of goods } \\
\text {-Optimization of technology } \\
\text {-Effective relationship with customers } \\
\text { environment and society (communication) } \\
\text { Dimension }\end{array}$ & $\begin{array}{c}\text {-Increase customer satisfaction } \\
\text {-Targeting customers who create the most } \\
\text { profitable. }\end{array}$ & -Uptimization of working capital \\
\hline -Local business support & employee satisfaction Dimension & learning and growing Dimension \\
-Leadership of communications & -Positive organizational culture & - Increase skills and capabilities of flexibility \\
-Connection with possible future employees & -contact with key customers & -The validation and authorization
\end{tabular}


In this section, to introduce quality management requirement, some of the important features of a quality system described as follows:

- Quality objectives and policies formulated;

- focus on the customer;

- directing all the activities to achieve objectives;

- Appropriate expertise of personnel tasks to achieve quality;

- control activities of specific customers;

- having criteria such as costs of quality and other criteria and standards of quality components;

- Corrective affirmative action;

- Continuous control of the system includes a feed-forward and feedback information and analysis of the results and to compare current standards, the periodic audit of the system actions (Ahire, et al., 1996).

As in the performance evaluation system by BSC used experts and specialists as quality and in terms of words; so measuring collecting opinions of the statistical population included by certain practices and non-fuzzy can be criticized by two reasons to ignore the ambiguous and subjective judgment. Using fuzzy concepts in the assessment can use verbal expressions as expressions with natural dialog language to assess the performance measurement indicators and by linking these expressions with the appropriate membership functions can apply more convenient and more accurate analysis on values of indicators (Brennan, 2010). Although the four BSC perspectives examine the performance of organizations at different levels of the organization to the level of business and personal, there is disadvantages and obstacles in the implementation of this model: First, there is no appropriate comprehensive perspective and common to all organizations and business units, hence, the user's experience and background play an important role in implementing this model. Secondly with the existence of diverse and abundant quantitative indicators in the scorecard has introduced the combination of specific and appropriate indicators. In traditional BSC is not provided also a way to express quantitative the relationship among higher levels (perspective and vision) and in practice, users should intuitively perform it. According to recent studies, in organizations that use the BSC to assess their performance, the causal relationship between the indicators before and after is often overlooked. Although a variety of information and opinions about strategy role and its impact in the BSC is available most organizations studied have not achieved good results align their strategy with operational terms (Kaynak, 2003). Multi-criteria decision-making methods can be combined to solve the problems stated with BSC. Decision-makers have expressed their opinions that reflect their real priorities to achieve the target because incomplete hierarchy can lead to inappropriate conclusions (Hung-Yi, et al., 2009). Stewart and Mohammad (2001) used the method of hierarchy and multi-attribute utility theory in the scorecard model and have developed a new method for evaluating the performance of organizations. Clinton Weber and Hösle (2002) used the hierarchical method to complete BSC. They pertained that since the first level of scorecard includes four perspectives and the second-level contains measurable indicators that are used in every aspect of it, hence hierarchical methods can be used to select measurement indicators and also help to understand the relative importance of indicators. Shan et al. (2003) studied the relationship between corporate strategy, environmental forces, and performance indicators of BSC. Analytic Hierarchy Process (AHP) in this study has been used to calculate the relative weight of performance indicators. In 2005, Chaing based on AHP and BSC suggested a dynamic approach for supplier selection problems. BSC model is used to define the four perspectives related to selecting the supplier and thus developing measurement indicators of perspectives. In this way, the structure of the hierarchical scorecard was investigated by AHP (Kaplan \& Norton, 2000).

\section{Material and Methods}

\subsection{Review of Literature}

Feizi et al. (2013) in the study with title: providing a model for performance measurement of municipalities and select construction companies in Tehran selection using techniques of fuzzy AHP and fuzzy TOPSIS and BSC, the results of the study show that using combined approach Fuzzy multiple criteria decision making with the BSC method can provide more tangible and practical results. Bentes et al. (2012) in this article to measure the organizational performance of Brazilian Telecom Company provided Integration of the BSC method and analytic hierarchy process (AHP). Table 2 shows a summary of research done about the use of BSC and fuzzy decision techniques. Feizi and Soloukdar (2014) in the study with title: performance evaluation of banking industry using FTOPSIS-BSC approach, introduced a new approach of strategic and decision-making techniques to assess banks in Alborz Province (Iran) in six perspectives: financial, customer, internal processes, learning and development, employee satisfaction and environment and society. In the researcher's opinion, the reason for adding two dimensions to four dimensions of performance measurement proposed and used by Professor Kaplan and Norton is too much importance due to employee satisfaction for organizational success and in achieving the organization's objectives and environment of changing and dynamic. The results of these researchers show that using the combined approach of decision-making and strategy and also use of the expressive spectrum in a Poll of experts can provide optimal assessment method and efficiency in the banking industry. Ghorbani (2013) in the article with title: Identify the key success factors in the establishment of comprehensive quality management in the automotive industry in Germany, researcher after careful study concerning the other researchers studies the key success factors in the establishment of comprehensive quality management in the automotive industry divided into four dimensions: process, management, quality and organizational. In the dimension of process, factors such as product design, customer satisfaction, 
the process of quality management and continuous improvement, in the dimension of management factors such as permanent support of senior management, building team consulting, continuing professional training and consulting employees, in the dimension of organizational factors such as teamwork, planning, structures and in the dimension of quality: focus on customer needs, quality culture and the role of the department of quality, supplier quality management be considered. After reviewing the results of his research In the automotive industry in Germany showed that each of the four factors mentioned is effective in the implementation and the establishment of quality management and factors of management, process, quality, and organization are ranks of first to the fourth and continuous support of senior management, supplier quality management and continuous training of employees respectively in terms of importance are in the rank of first to fourth. Hypotheses and factors were ranked using the mean of a society and Friedman test. Zarei Nejad and Hojati (2013), in the introduction, have suggested that the role of information technology in today's business and to improve its performance is imperative and information technology unit structure is significantly important and introduces an approach that based on fuzzy multi-criteria decision-making methods (FMCDM) and BSC (BSC), for evaluating the performance of IT departments use the banking system and the results will be used as a guide to improve the performance of IT departments in the banking system that support YASUJ (Iran) manufacturing industry and to improve the performance of manufacturing industry and services of banks. Formed information systems can also be used as an effective tool for solving problems Multi-Attribute Decision Making.

Table 2

Summary of accomplished researches about the evaluation of BSC

\begin{tabular}{|c|c|c|c|}
\hline Author & Year & Research subject & Tools used \\
\hline Feizi et al. & 2013 & Evaluation of construction companies in Tehran Municipality-Iran & BSC-FAHP-FTOPSIS \\
\hline $\begin{array}{l}\text { Boroojeni \& } \\
\text { Mirfakhroldini }\end{array}$ & 2012 & BSC in Hotel services & FTOPSIS \\
\hline $\begin{array}{l}\text { Zarei Nejad \& } \\
\quad \text { Hojati }\end{array}$ & 2013 & BSC to assess IT departments of the banking system & FMCDM \\
\hline Shahroodi et al. & 2011 & $\mathrm{BSC}$ in private banking of Iran & FAHP,TOPSIS,ELECTRE,VIKOR \\
\hline Momeni et al. & 2011 & BSC in private banks listed in the Tehran Stock Exchange & SAW \& VIKOR\& TOPSIS \\
\hline Feizi \& Soloukdar & 2014 & Performance Evaluation of Banking Industry using BSC & FTOPSIS \\
\hline Shavandi et al. & 2012 & Performance Evaluation of three Non-public banks & FMCDM \\
\hline Faramarz et al. & 2012 & Prioritization of entrepreneurship indicators based on BSC & VIKOR \\
\hline Jamshidian et al. & 2012 & Performance evaluation of Telecommunication Company in Ilam-Iran & $\begin{array}{l}\text { Use of documents and statistical } \\
\text { analysis }\end{array}$ \\
\hline Tahari Mehrjerdi & 2011 & Performance Evaluation of Cooperative General Office in Yazd province & VIKOR, FANP \\
\hline $\begin{array}{l}\text { Nazemi, Kazemi, } \\
\text { Okhravi }\end{array}$ & 2010 & Key success factors in TQM & AHP \\
\hline Motamedi et al. & 2010 & Strategic Performance Evaluation of banks & FAHP, TOPSIS \\
\hline Mehran & 2010 & Performance evaluation in 10 branches of banks & MCDM \\
\hline Mehrgan \& Nayeri & 2008 & Performance Evaluation of top management colleges in Tehran province & TOPSIS, BSC \\
\hline Hemati \& Asian & 2007 & Designing BSC in an industrial unit & FTOPSIS \\
\hline Alvandi \& Mansoori & 2007 & $\begin{array}{l}\text { BSC impact on the management of business processes in two Iranian } \\
\text { Organization }\end{array}$ & BSC \\
\hline $\begin{array}{c}\text { Hemati \& } \\
\text { Abdollahzadeh }\end{array}$ & 2007 & $\begin{array}{l}\text { Applying fuzzy theory in the BSC to evaluate the strategy of an } \\
\text { organization }\end{array}$ & FUZZY \\
\hline Eben Rasool et al. & 2004 & Designing BSC to Financial Deputy in Malek Ashtar University & BSC \\
\hline Sila, Ebrahimpour & 2002 & Research-oriented quality management & $\begin{array}{c}25 \text { factors of quality management } \\
\text { approach }\end{array}$ \\
\hline Bentes & 2012 & BSC in a Brazilian telecommunication company & AHP \\
\hline $\begin{array}{l}\text { Ebn Rasol \& Taghi } \\
\text { Nataj }\end{array}$ & 2010 & BSC in University & $\mathrm{BSC}$ \\
\hline
\end{tabular}

\subsection{The Methods}

To solve the problem in this research, a hybrid fuzzy MCDM approach according to the below has been proposed.

\section{Step 1: Fuzzy DEMATEL Technique}

DEMATEL technique is a decision-making method provided by Gabos \& Fontela in 1971 and It is based on paired comparisons, with the benefit of experts judgment in the extraction of a system factor and structuring systematic them using the principles of graph theory which provides a hierarchical structure of factors existing in a system with interaction relationships of impression and the effect so that is defined the intensity of mentioned relations as a numerical score. DEMATEL method is used to identify and evaluate the interaction between standards and to create mapping network relationships. When experts have expressed their opinions as fuzzy numbers, we use techniques of FDEMATEL (Kaplan, et al., 2000). The DEMATEL method is described as follows:

1. developing the questionnaire and collect relative dependence information of indicators in term of expert opinion;

2. Calculate direct relations matrix $(\mathrm{Z})$;

3. Calculate the normal direct relations matrix $(\mathrm{S})$;

4. Calculate the total relation matrix (direct and indirect dependence) $(\mathrm{T})$;

5. Calculate total relation normal matrix with the threshold of acceptance; 
6. The mapping consists of network relationships based on two vectors $\mathrm{D}$ and $\mathrm{R}$

Also to compare standards with each other, five verbal expressions equivalents of their fuzzy values are shown in Table 3.

Table 3

Verbal expressions used in research and equivalents values

\begin{tabular}{cc}
\hline Fuzzy value & Verbal Phrase \\
\hline$(0.00,0.10,0.30)$ & No impact \\
$(0.10,0.30,0.50)$ & Very little impact \\
$(0.30,0.50,0.70)$ & Less impact \\
$(0.50,0.70,0.90)$ & High impact \\
$(0.70,0.90,1.00)$ & Very high impact \\
\hline
\end{tabular}

First step: to consider the opinion of all experts, according to Eq. (1) take their arithmetic mean.

$$
\tilde{Z}=\frac{\tilde{x}^{1} \oplus \tilde{x}^{2} \oplus \tilde{x}^{3} \ldots \oplus \tilde{x}^{p}}{p}
$$

In this relation, $\mathrm{p}$ is the number of experts and $\tilde{\mathrm{X}}^{1}, \tilde{\mathrm{X}}^{2}, \tilde{\mathrm{X}}^{\mathrm{p}}$ are respectively paired comparison matrix of expert 1 , expert 2 and expert $\mathrm{p}$ and $\tilde{z}$ is triangular Fuzzy as $\tilde{z}_{i \mathrm{j}}=\left(l_{i j}^{\prime}, m_{i j}^{\prime}, u_{i j}^{\prime}\right)$.

Second Step: relation (2) uses to normalize the matrix obtained.

$$
\tilde{H}_{i j}=\frac{\tilde{z}_{i j}}{r}=\left(\frac{l_{i j}^{\prime}}{r}, \frac{m_{i j}^{\prime}}{r}, \frac{u_{i j}^{\prime}}{r}\right)=\left(l_{i j}^{\prime \prime}, m_{i j}^{\prime \prime}, u_{i j}^{\prime \prime}\right)
$$

That $r$ is obtained from Eq. (3):

$$
r=\max _{1 \leq i \leq n}\left(\sum_{i=1}^{n} u_{i j}\right)
$$

Third Step: calculate the above matrix, the matrix of fuzzy relations is obtained due to the relations $(4,5,6,7)$.

$$
T=\lim _{k \rightarrow \infty}\left(\widetilde{H}^{1} \oplus \widetilde{H}^{2} \oplus \ldots \oplus \widetilde{H}^{K}\right)
$$

That each element of a fuzzy number is as $\tilde{t}_{i j}=\left(l_{i j}^{t}, m_{i j}^{t}, u_{i j}^{t}\right)$ and is calculated with relations $(5,6,7)$ :

$$
\begin{aligned}
& {\left[l_{i j}^{t}\right]=H_{l} \times\left(I-H_{1}\right)^{-1}} \\
& {\left[m_{i j}^{t}\right]=H_{m} \times\left(I-H_{m}\right)^{-1}} \\
& {\left[u_{i j}^{t}\right]=H_{u} \times\left(I-H_{u}\right)^{-1}}
\end{aligned}
$$

In these formulas, I is the unit matrix and $H_{l}, H_{m}, H_{u}$ each of them is matrix $\mathrm{n} \mathrm{x} \mathrm{n}$ that its element form respectively lower number, middle number and high number of triangular fuzzy numbers for matrix $\mathrm{H}$

Fourth step: is to obtain the total rows and columns of a matrix $\tilde{T}$. Total rows and columns are obtained due to the relations (8 and 9).

$$
\begin{aligned}
& \tilde{D}=\left(\tilde{D}_{i}\right)_{n \times 1}=\left[\sum_{j=1}^{n} \tilde{T}_{i j}\right]_{n \times 1} \\
& \tilde{R}=\left(\tilde{R}_{i}\right)_{1 \times n}=\left[\sum_{j=1}^{n} \tilde{T}_{i j}\right]_{1 \times n}
\end{aligned}
$$

where $\tilde{D}$ and $\tilde{R}$ are respectively matrix $\mathrm{n} \times 1$ and $1 \times \mathrm{n}$. In next step is to determine the importance of the index $\left(\tilde{D}_{i}+\tilde{R}_{i}\right)$ and the relationship between criteria $\left(\tilde{D}_{i}-\tilde{R}_{i}\right)$. If $\tilde{D}_{i}-\tilde{R}_{i}>0$, the related criterion is affecting and if $\tilde{D}_{i}-\tilde{R}_{i}<0$ the related criterion is affected. In the next step, fuzzy numbers $\tilde{D}_{i}+\tilde{R}_{i}$ and $\tilde{D}_{i}-\tilde{R}_{i}$ obtained from the previous step we defuzzify according to Eq. (10).

$$
B=\frac{\left(a_{1}+a_{3}+2 \times a_{2}\right)}{4}
$$

B defuzzified is number $\tilde{A}=\left(a_{1}, a_{2}, a_{3}\right)$. 


\section{Step 2: Fuzzy ANP technique}

The network analysis process or ANP is another series of decision-making techniques that were presented by Prof. Saati to develop the Analytical Hierarchy Process and is very similar to the AHP method. Each of the methods is based on a set of assumptions. For example, if the criteria are independent of each other and pairwise comparisons are possible, a suitable decision-making model is the AHP model. But if the criteria were not independent, the ANP method is better. When we use expressive numbers and fuzzy to fill the matrix of paired comparisons, the fuzzy ANP technique must be used (Momeni, et al., 2011; Dalvi \& Kant, 2017; Feyzi \& Solokdar, 2014).

\subsection{Survey Research}

Survey research is the most common type of social science research that its base is a survey of those who are directly involved in research issues (Neely, 2003). Considering that the purpose of this study is to identify effective indicators in performance measurement of a firm using the BSC approach, therefore, the survey research will be used for the first part of this study. The most important benefits of this research are the ability to generalize the results. About the purpose, motivation, and benefits of this research, it is a kind of applied research because its results will be used to adjust the plans of the organization (Company firm). The statistical population of the current study includes 150 experts and managers of a Company firm that In this study, the sample size (managers and experts) obtain 108 persons using the Cochran formula. To collect data in this study used two questionnaires:

Questionnaire No. 1: Questionnaires of pairwise comparisons and fuzzy DEMATEL techniques.

Questionnaire No. 2: for the ranking indicators of evaluating Company firm using techniques of fuzzy ANP.

In the present study to determine validity is used content validity (verification of the quantity and quality of questions in terms of experts and professors related to the field of research). To determine the reliability of the questionnaire, the compatibility technique of Gogus \& Boucher has been applied. A complete review of a management phenomenon requires a suitable conceptual model. Framework or conceptual model shows theoretical relationships between important variables studied (M.Liand, 2007). After library studies and extraction of service companies' performance evaluation indicators of previous research, indicators extracted from the chart (1), the executive model, and Figure 1 shows a conceptual model of research.

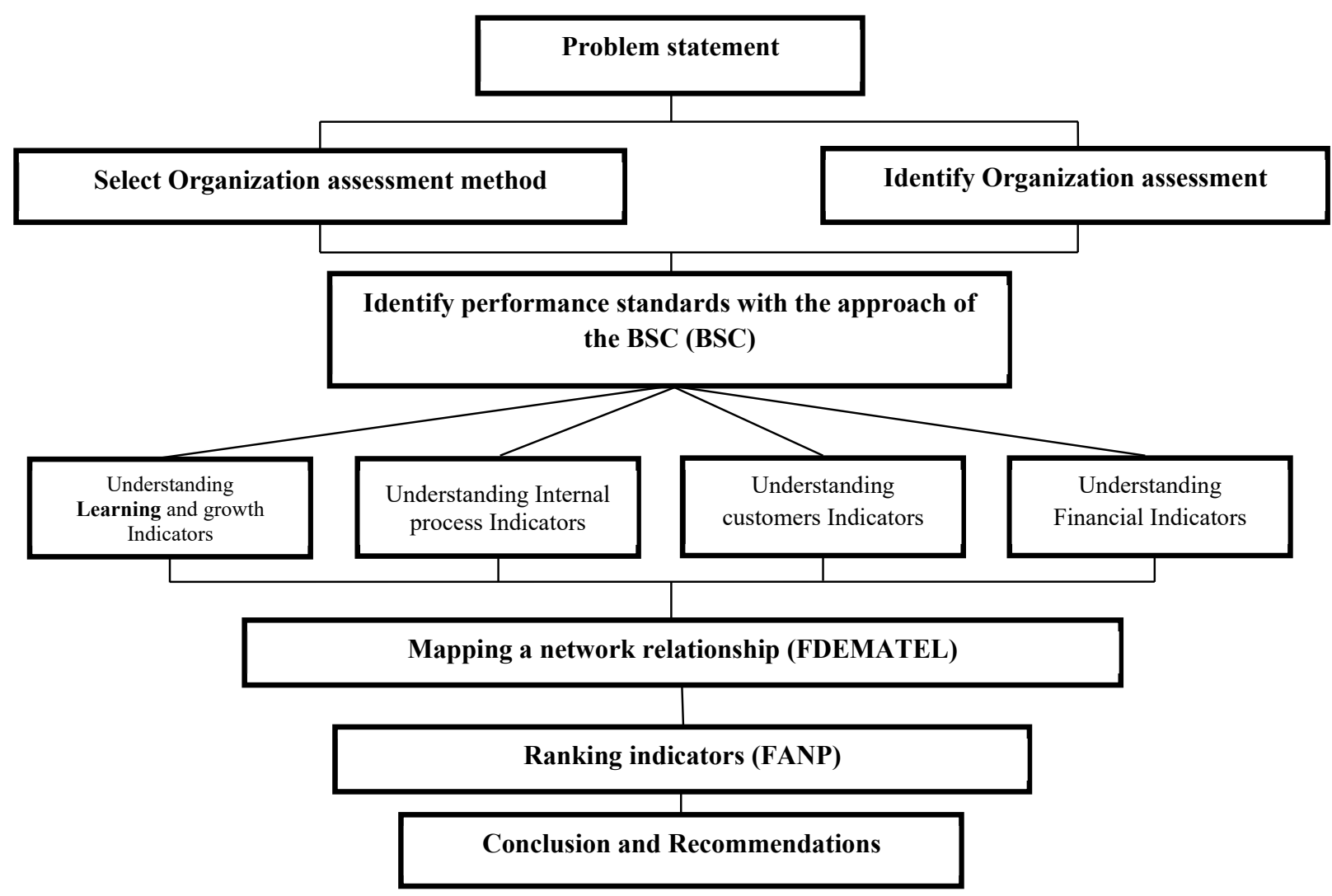

Fig. 1. Executive model of Research 
$\mathrm{n}$ the conceptual model, perspectives include 4 dimensions of the BSC. Line 3 determines research tools and line 4 determines proper weighting and ranking.

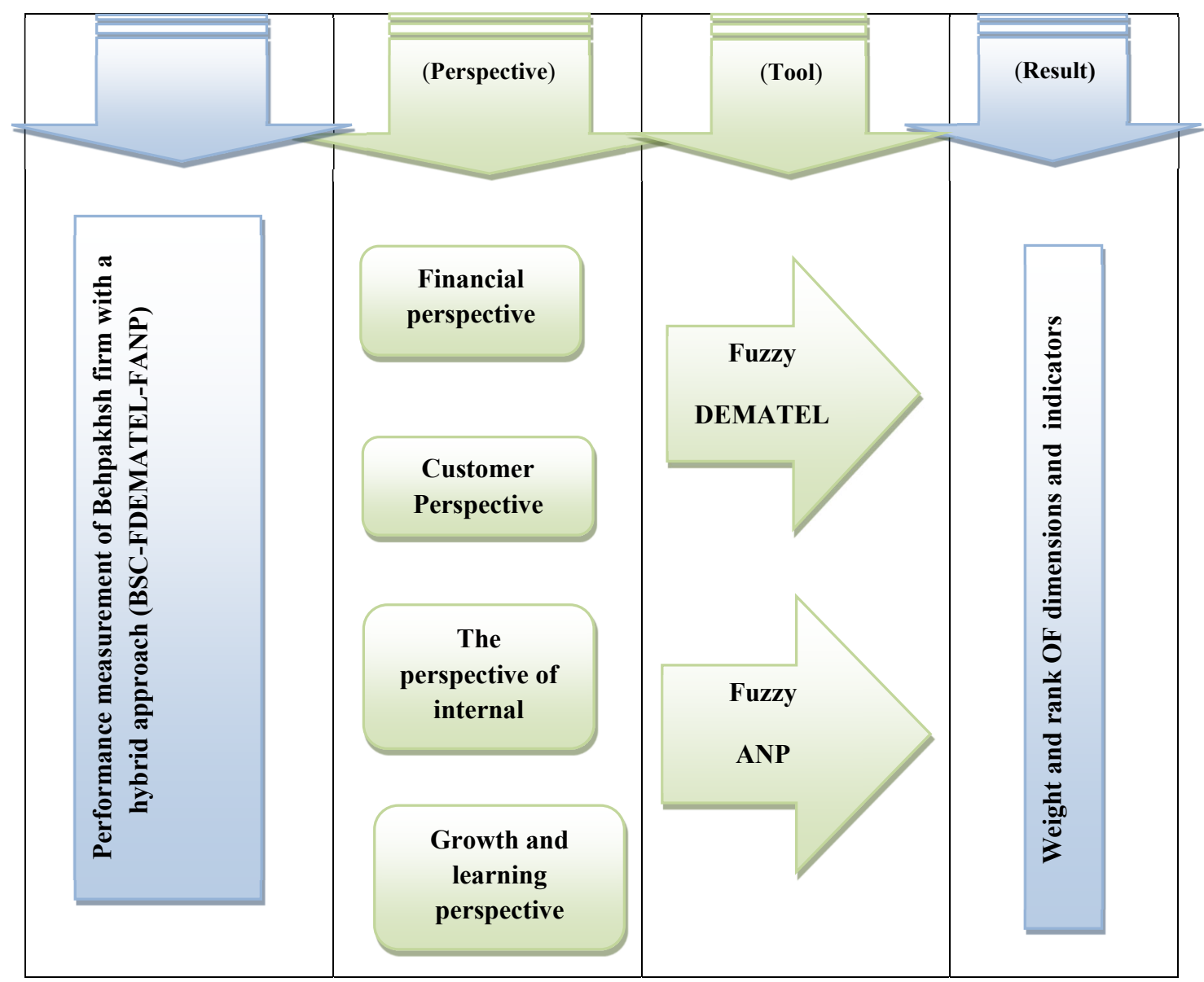

\section{Results And Discussion}

Fig. 3. Conceptual Model of Research

The purpose is weighting and ranking indicators to assess the performance of the Company firm. A manufacturing company begins with the awareness that to provide a cheap product, quality, and best service, it is needed for the role of all parties related to the production process in a firm. This aspect can run well and need the role of all parties beginning suppliers who manage raw material from nature to become factory components, the factory is changed from raw material to finished product, transportation firms send raw material from a supplier and connect distribution products to consumers. The importance of awareness of all the parties can be raising supply chain management. (Pujawan, 2010). Supply Chain is the firms' network together to create and bring a product to an end-user hand. The firms usually include supplier, factory, distributor, store or retail, and supporting firms like logistic service firms (Chopra and Meindl, 2007). A strategy of the supply chain is a responsive strategy and efficient strategy. Creating a responsive strategy can be done with market research with batter, so it can capture market wanted, and speed response of market wanted. The responsive strategy is a strategy that contains the ability supply chain to respond and solve the request with the big amount to fulfill a need in the near time, solve much product variant, give high service to consumers, and solve uncertainty of request. More high ability of supply chain in each activity, will progressive a firm, however, the cost issued by the firm also will be high (Chopra \& Meindl, 2007).

\subsection{Statistical population}

The population includes 150 experts and managers of Company firms that in this study, to estimate the sample size (managers and experts) is used from the formula of determining the sample size with the finite population. The following relation determines the finite population sample size (Moemeni \& Ghaumi, 2011).

$$
\mathrm{n}=\frac{\mathrm{N} \times\left(\mathrm{Z}_{\alpha / 2}\right)^{2} \times \mathrm{pq}}{(\mathrm{N}-1) \times(\varepsilon)^{2}+\left(\mathrm{Z}_{\alpha / 2}\right)^{2} \times \mathrm{pq}}
$$


$Z=$ Trust factor to Trust factor (1.96)

$\boldsymbol{\varepsilon}=$ Error (typically from 0.05 to 0.1 )

$\mathrm{N}=$ the number of people in society

$\mathrm{P}=$ the ratio of success in society (To maximize sample size $\mathrm{p}=\mathrm{q}=0.5$ )

$\mathrm{n}=$ sample size

$$
n=\frac{150 \times(1.96)^{2} \times 0.5 \times 0.5}{(149) \times(0.05)^{2}+(1.96)^{2} \times 0.5 \times 0.5} \cong 108
$$

So number of samples is calculated 108 people.

\subsection{Identify and evaluate the relationship between measures and the mapping of network relationships with} fuzzy DEMATEL

The first step: forming a matrix of pairwise comparisons and the mean of the expert's importance.

After confirming questionnaire (1) of research (validity and reliability), was distributed among 108 experts of Company firm. After collect judgments, table (4) shows pairwise comparison means obtained from expert opinion about dimensions.

\section{Table 4}

Mean of expert opinion about dimensions of BSC

\begin{tabular}{ccccc}
\hline Dimensions & Financial & Customers & Internal processes & Growth and learning \\
\hline Financial & $(0,0,0)$ & $(0.567,0.767,0.900)$ & $(0.567,0.767,0.900)$ & $(0.500,0.700,0.867)$ \\
Customers & $(0.067,0.233,0.433)$ & $(0,0,0)$ & $(0.267,0.433,600)$ & $(0.267,0.433,0.600)$ \\
Internal processes & $(0.1,0.233,0.433)$ & $(0.485,0.549,0.645)$ & $(0,0,0)$ & $(0.167,0.367,567)$ \\
Growth and learning & $(0.267,0.433,0.633)$ & $(0.500,0.700,0.867)$ & $(0.567,0.767,0.933)$ & $(0,0,0)$ \\
\hline
\end{tabular}

Second Step: normalizing group decision matrix

Table 5 shows matrix normalized (normalized matrix)

Table 5

Matrix normalized relative to the dimensions of BSC

\begin{tabular}{ccccc}
\hline Dimensions & Financial & Customers & Internal processes & Growth and learning \\
\hline Financial & $(0,0,0)$ & $(0.025,0.0340,0.040)$ & $(0.025,0.034,0.040)$ & $(0.022,0.031,0.039)$ \\
Customers & $(0.003,0.010,0.019)$ & $(0,0,0)$ & $(0.012,0.019,0.027)$ & $(0.012,0.019,0.027)$ \\
Internal processes & $(0.004,0.010,0.019)$ & $(0.022,0.031,0.039)$ & $(0,0,0)$ & $(0.007,0.016,0.025)$ \\
Growth and learning & $(0.012,0.019,0.028)$ & $(0.022,0.031,0.039)$ & $(0.025,0.034,0.042)$ & $(0,0,0)$ \\
\hline
\end{tabular}

Third Step: Calculate Matrix $\tilde{T}$

Table 6 shows matrix t.

Table 6

Total relationships Matrix of BSC dimensions

\begin{tabular}{ccccc}
\hline Dimensions & Financial & Customers & Internal processes & Growth and learning \\
\hline Financial & $(0.018,0.072,0.588)$ & $(0.049,0.122,0.712)$ & $(0.046,0.116,0.688)$ & $(0.042,0.111,0.676)$ \\
Customers & $(0.018,0.074,0.559)$ & $(0.020,0.078,0.618)$ & $(0.030,0.092,0.622)$ & $(0.029,0.090,0.613)$ \\
Internal processes & $(0.021,0.080,0.589)$ & $(0.044,0.155,0.690)$ & $(0.020,0.079,0.629)$ & $(0.027,0.094,0.644)$ \\
Growth and learning & $(0.028,0.087,0.596)$ & $(0.044,0.114,0.688)$ & $(0.044,0.111,0.668)$ & $(0.019,0.076,0.618)$ \\
\hline
\end{tabular}

Fourth Step: obtain sums of rows and columns of a matrix

Table 7 shows the importance and effectiveness of BSC dimensions with fuzzy numbers.

Table 7

The importance and effectiveness of BSC dimensions (fuzzy numbers)

\begin{tabular}{ccc}
\hline Dimensions & $\tilde{D}_{i}+\tilde{R}_{i}$ & $\tilde{D}_{i}-\tilde{R}_{i}$ \\
\hline Financial & $(1.994,5.547,35.2,2)$ & $(-15.369,+0.580,17.839)$ \\
Customers & $(2.091,5.748,36 ., 75)$ & $(-17.967,-372,16.017)$ \\
Internal processes & $(2.1,2,5.778,36.359)$ & $(-17.169,-0.068,17.084)$ \\
Growth and learning & $(2.040,5.673,36.037)$ & $(-16.444,+0.3 .306,17.614)$ \\
\hline
\end{tabular}


Fifth step: Defuzzify fuzzy numbers $\tilde{D}_{i}+\tilde{R}_{i}$ and $\tilde{D}_{i}-\tilde{R}_{i}$

Table 8 shows numbers defuzzified of the Table 7.

Table 8

Importance and influence of dimensions (absolute numbers)

\begin{tabular}{ccc}
\hline Dimensions & $\tilde{D}_{i}+\tilde{R}_{i}{ }^{\text {def }}$ & $\tilde{D}_{i}-\tilde{R}_{i}^{\text {def }}$ \\
\hline Financial & 12.073 & 0.907 \\
Customers & 12.416 & -0.673 \\
Internal processes & 12.504 & 0.014 \\
Growth and learning & 12.355 & 0.091 \\
\hline
\end{tabular}

Figure 3 also shows the importance and influencing and influenced between dimensions. The horizontal axis shows the importance of dimensions and the vertical axis shows influencing or influenced by BSC dimensions.

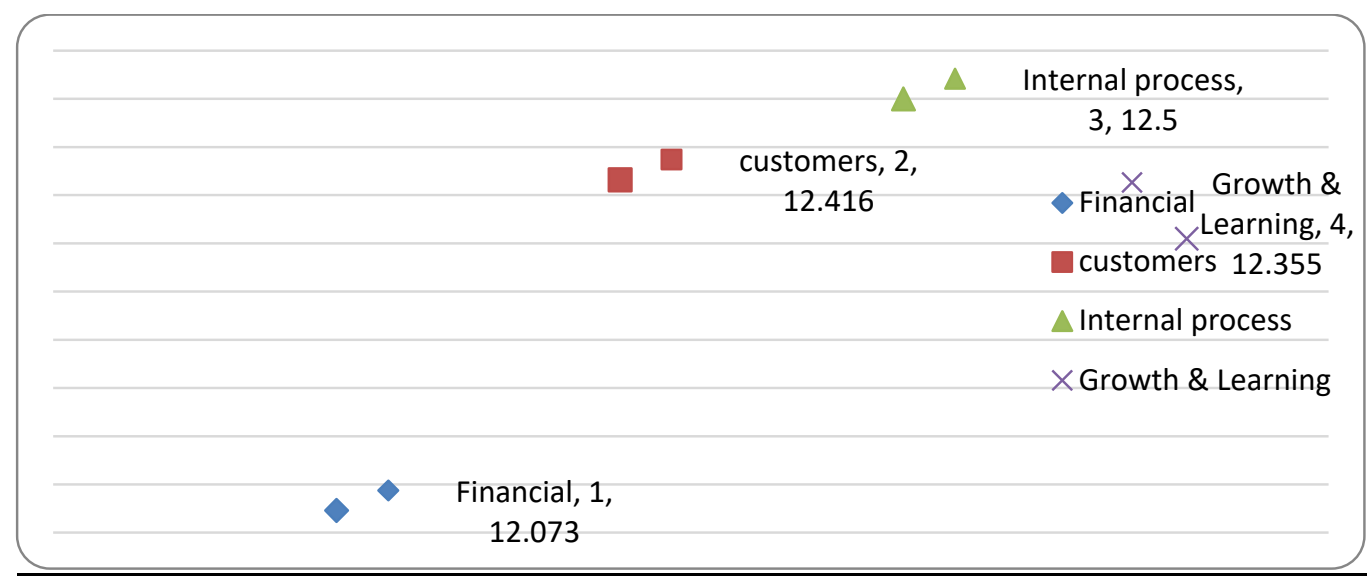

Fig. 3. The relationship and the importance of BSC dimensions

\section{5-4- steps of obtaining the weight of indicators and dimension using fuzzy network analysis}

First and second steps: the geometric mean of experts pairwise comparisons and calculate eigenvector. To gather expert opinions are calculated the geometric mean from the pairwise comparisons of respondents. To calculate eigenvector of aggregated tables paired comparisons, according to the relation (11) is used logarithmic least squares method.

$$
w_{k}^{s}=\frac{\left(\prod_{j=1}^{n} a_{k j}^{s}\right)^{1 / n}}{\sum_{i=1}^{n}\left(\prod_{j=1}^{n} a_{i j}^{m}\right)^{1 / n}}, \quad s \in\{l, m, u\}
$$

So that:

$\widetilde{w}_{k}=\left(w_{k}^{l}, w_{k}^{m}, w_{k}^{u}\right) \quad k=1,2,3, \ldots, n$

Table 9 shows the geometric mean of expert opinions. In the last line of the table is shown the incompatibility rate of dimensions.

Table 9

Mean of pairwise comparisons to BSC dimensions

\begin{tabular}{|c|c|c|c|c|c|}
\hline $\begin{array}{c}\text { Ranking } \\
\text { Performance } \\
\text { dimensions }\end{array}$ & Financial & Customers & Internal processes & Growth and learning & Eigenvector \\
\hline Financial & $(0,0,0)$ & $(0.816,1.155,1.414)$ & $(1,1.225,1.225)$ & $(0.309,0.371,0.397)$ & $(0.419,0.464,0.552)$ \\
\hline Customers & $(0.707,0.866,1.225)$ & $(0,0,0)$ & $(1,1.414,1.414)$ & $(0.295,0.354,0.397)$ & $(0.451,0.536,0.593)$ \\
\hline Internal processes & $(0.816,0.816,1)$ & $(0.727,0.707,1)$ & $(0,0,0)$ & $(0.275,0.275,0.331)$ & $(0.482,0.634,0.634)$ \\
\hline Growth and & $(0.823,0.816,1)$ & $(0.297,0.602,1)$ & $(0.542,0.314,0.743)$ & $(\mathbf{0 , 0 , 0 )}$ & $(0.366,0.366,0.482)$ \\
\hline \multicolumn{6}{|c|}{$\begin{array}{r}\mathrm{CR}^{\mathrm{m}}=0.009 \text { Harmonic } \\
\text { C }\end{array}$} \\
\hline
\end{tabular}


Third step: the formation of eigenvector matrices $\left(W_{i j}\right)$

These matrices include eigenvectors that were obtained pairwise comparisons in the second step.

In general, these matrices can be divided into two categories:

Matrix with eigenvector shows the relationship between levels (vertical). If between two components there is no relationship between the levels (If there is no relationship among the levels of two components). In confluence of these two components in the matrix is (are) values $(0,0,0)$. In other elements, too, according to the vertical relationship of the component are eigenvector values obtained from the second step.

Matrix with eigenvector that shows horizontal relationships (within levels). This matrix is square and its diagonal is $(0,0$, 0 ) if between two components there is no relationship within levels at the confluence of the two components in the matrix is the value $(0,0,0)$. In other elements are also according to horizontal relationships and are placed as an eigenvector.

Note that if in an eigenvector matrix within the levels, one or more elements in the main diameter don't become $(0,0,0)$ because thatcolumn has been done normalized.. Normalization is so that all fuzzy numbers of the columns are divided by the sum of the median values of Fuzzy numbers in that column.

Fourth Step: calculate the final weights of levels

To calculate the final weighing of the components $\left(W_{i}^{*}\right)$ must multiply the eigenvector matrix by internal eigenvector at the same level in the final weight of a higher level.

$$
W_{i}^{*}=W_{i i} \times W_{i(i-1)} \times W_{i-1}^{*}
$$

If there is not for a level a matrix of $W_{i i}$, it is necessary for a unit matrix with the same degree to replace it. In other words, should use from relation (13).

$$
W_{i}^{*}=I \times W_{i(i-1)} \times W_{i-1}^{*}
$$

After gaining fuzzy weights of performance measurement dimensions for the firm should become fuzzy numbers to defuzzification (absolute). Various methods exist for definitive fuzzy numbers including the mean method and center of gravity. The present study is used as the center of gravity for the defuzzification of fuzzy numbers. If a triangular fuzzy number is as $\mathrm{M}=(\mathrm{a}, \mathrm{b}, \mathrm{c})$ Eq. (14) shows how to calculate the definitive fuzzy numbers to show:

$$
C A=\frac{(c-a)+(b-a)}{3}+a
$$

Table 10 Table 11 and Fig. 4 and Fig. 5 show final weights of dimensions and indicators of performance measurement in a Company firm using the BSC approach.

Table 10

The final weights matrix of BSC dimensions with fuzzy ANP

\begin{tabular}{ccccc}
\hline Rank & $\begin{array}{c}\text { final decisive Weight of } \\
\text { BSC dimensions }\end{array}$ & Weight of the final phase & Dimensions & Financial \\
\hline 2 & 0.483 & $(0.07,0.6,0.78)$ & Customers & Internal processes \\
3 & 0.617 & $(0.7,0.8,0.35)$ & Growth and learning \\
\hline
\end{tabular}

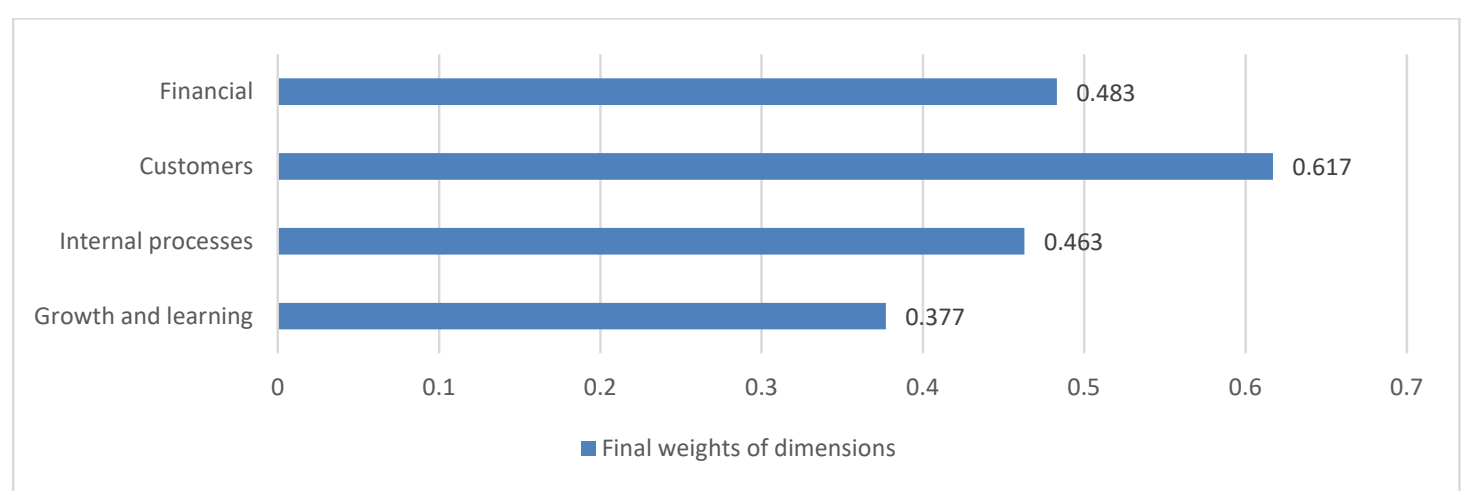

Fig. 4. Chart of The Final Weights for BSC Dimensions 
Table 11

The final weights matrix of BSC indicators with fuzzy ANP

\begin{tabular}{|c|c|c|c|}
\hline Indicators & Weight of the final phase & $\begin{array}{l}\text { final decisive Weight } \\
\text { of BSC dimensions }\end{array}$ & Rank \\
\hline Correct management of Portfolio and risk & $(0.751,1,1)$ & 0.450 & 3 \\
\hline $\begin{array}{l}\text { Reporting and Permanent monitoring of financial } \\
\text { indicators }\end{array}$ & $(1,1,1)$ & 0.464 & 1 \\
\hline $\begin{array}{l}\text { Survey Statistics of purchases and sales and interest in the } \\
\text { stock market to brand }\end{array}$ & $(0.799,1,1)$ & 0.463 & 2 \\
\hline Continuous surveys of customers about the quality & $(0.723,1,1)$ & 0.437 & 4 \\
\hline $\begin{array}{l}\text { Survey chain stakeholders as a major distributor, retailer, } \\
\text { and recycler }\end{array}$ & $(0.605,1,1)$ & 0.430 & 6 \\
\hline $\begin{array}{l}\text { Identify the best brands, successful experiences, and } \\
\text { models from the client as benchmarking }\end{array}$ & $(0.616,1,1)$ & 0.432 & 5 \\
\hline Investigate customer complaints & $(0.481,0.799,1)$ & 0.426 & 7 \\
\hline $\begin{array}{l}\text { Using the system of Performance management and } \\
\text { reward }\end{array}$ & $(0.182,0.655,0.731)$ & 0.402 & 10 \\
\hline $\begin{array}{l}\text { The existence of information technology tools for } \\
\text { continuous monitoring }\end{array}$ & $(0.188,0.825,1)$ & 0.420 & 9 \\
\hline $\begin{array}{l}\text { Regular processes of review and implementation of } \\
\text { policy }\end{array}$ & $(0.188,0.845,1)$ & 0.425 & 8 \\
\hline Training and capacity building & $(0.149,0.799,1)$ & 0.395 & 11 \\
\hline Identify vision, mission, and main objectives & $(0.123,0.731,1)$ & 0.394 & 12 \\
\hline Review and training lessons learned & $(0.109,0.731,1)$ & 0.385 & 13 \\
\hline
\end{tabular}

According to Table 11, reporting and permanent monitoring of financial indicators obtain the first rank and other indicators obtain ranks of second to thirteenth.

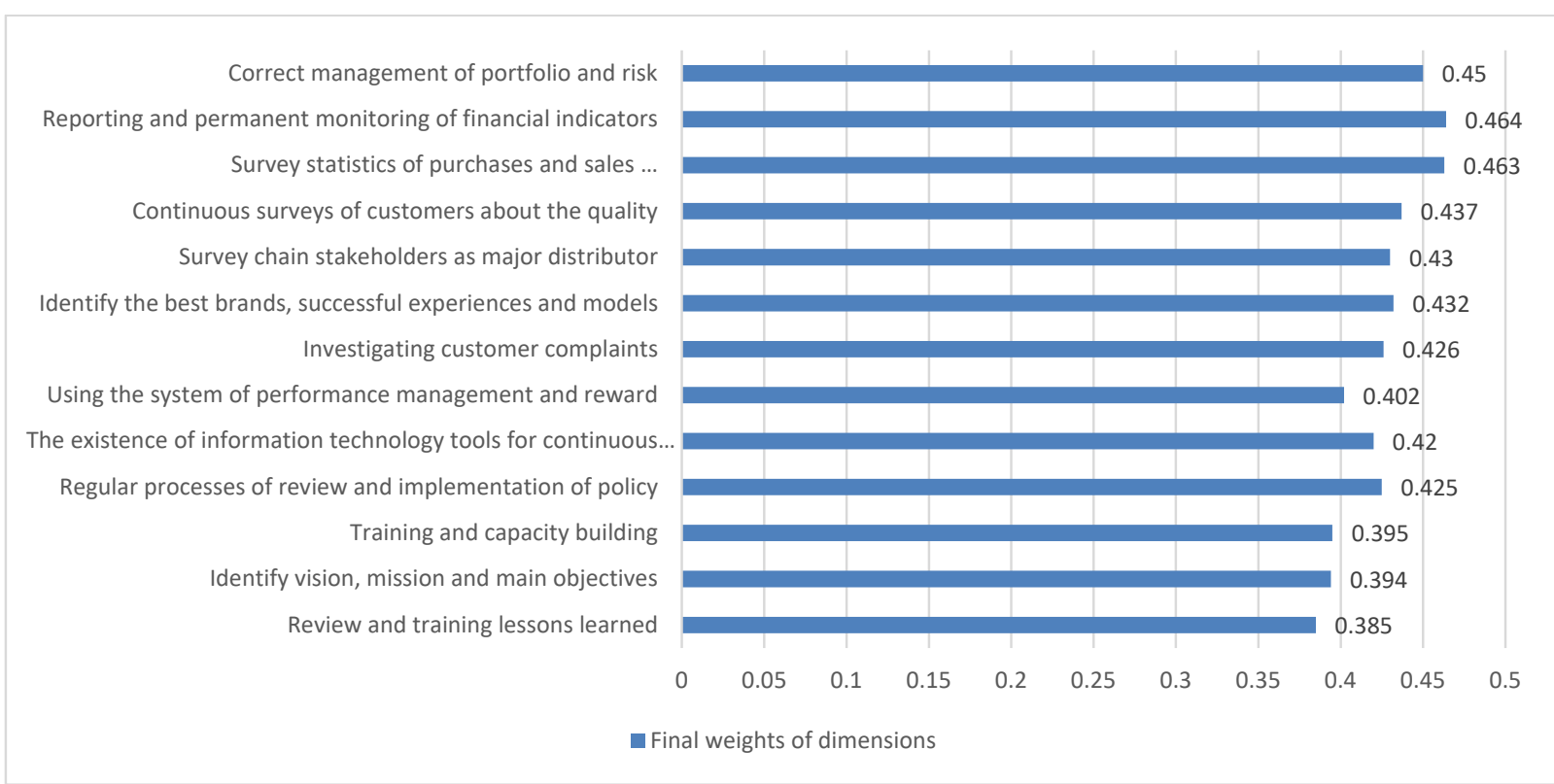

Fig. 5. The final weights chart of BSC indicators

\section{Conclusion and Recommendations}

Records indicated numerous researches related to the performance measurement of manufacturing and business service companies with the BSC approach and decision-making techniques. Including Feizi and et al. (2013) assess construction companies in Tehran Municipality with the approach of FTOPSIS-FAHP-BSC. Shahverdi et al. (2011) with the BSC approach identify indicators in every perspective and weighting with fuzzy AHP and decision-making techniques TOPSIS, ELECTRE, and VIKOR evaluate and ranking private banks; Moemeni et al. (2011) evaluate and ranking banks listed in Tehran Stock Exchange with BSC approach and decision-making techniques of SAW, VIKOR, and TOPSIS weighted indexes and ranked banks. Continue to investigate cases of similarities and differences between the results of this study with researchers described above and expression of possible reasons for creation of the similarities and differences. Hemati \& Asian (2007) designed BSC using fuzzy TOPSIS. They in proposal algorithm in an industrial unit was used in combination with classic and fuzzy TOPSIS, concluded that techniques for Multiple Attribute Decision Making (MADM) fuzzy, such as fuzzy TOPSIS can use by a structured methodology, in the design of the BSC as a system of measurement and 
performance management based on strategy. Also, they concluded that the model of proposal scorecard based on fuzzy TOPSIS by providing systematic solutions obtained from feedback systems create improvement in almost all indicators defined and has had a positive impact on organizational performance in all dimensions.

The present study has investigated the importance and impact dimensions of performance measurement in a Company firm in four perspectives of financial, customers, internal processes, and learning growth with the approach of BSC and weighting dimensions and indicators with fuzzy DEMATEL approach and ranking dimensions and its indicators with fuzzy ANP approach. In this section, we referred to common points of the present study with researchers mentioned in the background of research and especially the research cited above. Feizi et al. (2013) has reviewed the performance of Construction Company in Tehran Municipality with the BSC approach in six perspectives: financial, stakeholder, processes, learning and growth and employee satisfaction and the environment and community and present study have identified measurement indicators in Company firm in four common perspectives. In the study Feizi et al. (2013) used the technique of fuzzy AHP for weighting and ranking of indicators and perspectives but the present study uses Fuzzy ANP techniques. The strengths of the present study compared to the research of Feizi and et al. is in the use of fuzzy network analysis and considering network relationships between dimensions and indicators of BSC that have not been considered in their research. Also, the use of fuzzy DEMATEL technique that determines the relationship between mapping network among dimensions of influencing percentage and experts focus on more important dimensions that study of Feizi (2013) has been deprived of. In the study of Feizi et al. (2013) financial dimension had gained the first rank and in the current study customers dimension gained the first rank using the ANP technique that derived from differences in the territory of subject and experts views and the role of customers in Company firm and service companies. According to the results of research and studies and surveys from domestic and foreign articles for the development of this research, the following recommendations are offered:

- The establishment of the voice of the customer is to review the comments and censures and offers of customers to satisfy most of them.

- Evaluation of the training needs of staff and in-service courses to enhance the capabilities of employees at work and dealing with customers.

- Supplying and distributing proper training packages in the branches and providing accurate and complete information about every person related to job duties.

- More attention to the strategic plans and targeted and check the performance of a service company due to the program established.

Although random questionnaire distribution is one of the research methods that are able to meet the investigator's demand, It is recommended to survey the subject mentioned less than the number of questionnaires used and be used from other methods of questionnaire distribution which is not known for the researcher.

Another recommendation is that fewer criteria be used (can be used) in future research and be used other methods of decision-making such as TOPSIS and (other methods of decision-making such as TOPSIS can be applied) then implementing results obtained are compared with these results (then a simple comparison can be implemented between the results).

\section{Acknowledgment}

The authors greatly acknowledge the support from the University of 17 Agustus 1945, UNTAG Surabaya Indonesia for providing the necessary resources to carry out this research. The authors are also grateful to the anonymous reviewers and journal editorial board for their many insightful comments, which have significantly improved this article.

\section{References}

Alam Tabriz, A., \& Mohammad Rahimi, A. (2009). Production Management and Operations Management Approaches in the Evaluation and Improvement of Business Processes, Commercial Publishing.

Ahire, S.L., Golhar, D.Y., \& Waller, M.W. (1996). Development and validation of TQM implementation constructs. Decision Sciences, 27(1), 23-56.

Brennan, L. (2010). Total quality management in a research and development Environment. Integrated Manufacturing Systems, 12(2), 94-102.

Clinton, D., Webber, S.A., \& Hassel, J.M. (2002). Implementing the balanced scorecard using the analytic hierarchy process. Management Accounting Quarterly, 3, 1-11.

Ebn Rasol, S.A., \& Taghi Nataj, Gh. (2010). Designing BSC model to finance duty in Malek Ashtar University. Iranian Journal of Human Sciences, 17(74).

Feyzi, A., \& Solokdar, A. (2014). Evaluating the performance of the banking industry with a combination approach (FTOPSIS-BSC). Journal of Engineering financial and management of securities, Islamic Azad University Central Tehran Branch, No. 20. 
Falsafi, N., Mozafari, M.M., \& Yousefi Zanoor, R. (2010). Comparing decision-making techniques of FTOPSIS \& TOPSIS in the evaluation of staff performance (case study: Kayson Company). Qazvin International University, A master's thesis.

Gogus, O., \& Boucher, T. (1998). Strong transitivity, rationality and weak monotonicity in fuzzy pairwise comparisons. Fuzzy Sets and Systems, 94(1), 133 - 144.

Hemati, M., \& Abdolahzadeh, R. (2007). Application of fuzzy theory in the Balanced Scorecard to assess the current strategies for the organization. Management Perspective, 6(7).

Hung-Yi, W., Gwo-Hshiung, T., \& Yi-Hsuan, Ch. (2009). A fuzzy MCDM approach for evaluating banking performance based on Balanced Scorecard. Expert Systems with Applications, 36, 10135-10147.

Kaplan., R.S., and Norton, D.P. (2007). Strategy - focused organization. Industrial Management Organization Press, Iran.

Kaplan, R.S., \& Norton, D.P. (2000). The Strategy-Focused Organization: How BSC companies Thrive in Business Environment. Harvard Business School Press model.

Kaplan., R.S., \& Norton, D.P. (2000). If you have a problem with your strategy, it will draw. Iranian journal of Management Selection, 3, 85.

Kateb, Gh., \& Hasanabadi, M. (2007). The establishment of the operational budget system using the BSC and activity-based costing. Iranian Journal of Peyk Noor, 4.

Khorshid, S., \& Zabihi, R. (2010). A quantitative model to evaluate brand equity of products using fuzzy network analysis techniques and data envelopment analysis based on the BSC. International Journal of Industrial Engineering and Production Management, 1 .

Karsalari, S.Gh., \& Hashemi, Z. (2012). Performance evaluation of Distribution of Foodstuff companies using the Balanced Scorecard with the approach of selecting indicators by AHP Fuzzy Delphi (FDAHP) Broadcasting Corporation shadiavaran. College of Management, Central Tehran Branch Master's thesis.

Dalvi, M. V., \& Kant, R. (2017). A survey on selected supplier issues in Indian manufacturing organisations. International Journal of Services and Operations Management, 27(2), 210-238.

Kaynak, H. (2003). The relationship between total quality management practices and their effects on firm performance", Journal of Operations Management, 21(4), 405-435.

M, Liand J.B. (2007). Yung Manchester school of management, UMIST, A decision model for self-assessment of a business process based on the EFQM excellence.

Momeni, M., \& Faal Ghayomi, M. (2011). Software Transactional training SPSS.

Momeni, M., Maleki, H., \& Mohammad, E.(2011). A fuzzy MCDM approach for evaluating listed private banks in Tehran Stock Exchange Based on BSC. International Journal of Business Administration, 2(1).

Mehrgan, M., \& Nayeri, M. (2008). Integrated approach BSC-TOPSIS to the assessment of top in management faculties Universities of Tehran. Journal of Industrial Management, 1(2).

Neely, B. (2003). Implementing Performance Measurement Systems. Journal of Business Performance Management, $5(1)$.

Nelly, A. (1999). The performance measurement revolution: Why now and what next?. International Journal of Operational Research, 46, 282-294.

Nilipour Tabatabaei, S.A., Bagherzadeh Niri, M., \& Shaabani Sichani, M. (2007). Designing Functional model of performance measurement of maintenance systems. The Fifth International Conference on Management.

Rezaei Ghahraman, M.R., \& Agha Hosseini, S.R. (2011). Twelve steps to develop and implementation of BSC and determine performance indicators.

Sila, I., \& Ebrahimpour, M. (2002). An investigation of the total quality management survey-based research published between 1282 and 2000. International Journal of Quality \& Reliability Management, 12(2), 202-220.

Stwart, R. A., \& Mohamed, S. (2001). Utilizing the balanced scorecard for IT/IS performance evaluation in construction. Construction Innovation, 11, 147-163.

Valmohammadi, C., \& Foroozeh, N. (2010). Performance measurement using technique of BSC (case study). Journal of Management, 18.

Zhang, Z. (2000). Developing a model of quality management methods and evaluating their effects on business performance. Total Quality Management, 11(1), 122-132.

Zarei Nejad, M., \& Hojati, M. (2014). A new method for weighing the demands of the customers and prioritize the technical characteristics of the product with fuzzy QFD approach. 
(C) 2021 by the authors; licensee Growing Science, Canada. This is an open access article distributed under the terms and conditions of the Creative Commons Attribution (CC-BY) license (http://creativecommons.org/licenses/by/4.0/). 